\title{
Evaluation of Heparin Anticoagulation Protocols in Post-Renal Transplant Recipients (EHAP-PoRT Study)
}

\author{
Joan Chung Yan Ng, Marianna Leung, and David Landsberg
}

\begin{abstract}
Background: Disturbances in hemostasis are common among renal transplant recipients. Because of the risk of thromboembolism and graft loss after transplant, a prophylactic heparin protocol was implemented at St Paul's Hospital in Vancouver, British Columbia, in 2011. Therapeutic heparin is sometimes prescribed perioperatively for patients with preexisting prothrombotic conditions. There is currently limited literature on the safety and efficacy of heparin use in the early postoperative period.

Objectives: The primary objectives were to document, for patients who underwent renal transplant, the incidence of major bleeding and of thrombosis in those receiving therapeutic heparin, prophylactic heparin, and no heparin anticoagulation in the early postoperative period and to compare these rates for the latter 2 groups. The secondary objectives included a comparison of the risk factors associated with major bleeding and thrombosis.
\end{abstract}

Methods: Adult patients who received a renal transplant at St Paul's Hospital between January 2008 and July 2013 were included in this retrospective cohort study. Electronic health records and databases were used to divide patients into the 3 heparin-use cohorts, to identify cases of major bleeding and thrombosis, and to characterize patients and events. The Fisher exact test was used for the primary outcome analysis, and descriptive statistics were used for all other outcomes.

Results: A total of 547 patients were included in the analysis. Major bleeding was observed in $6(46 \%)$ of the 13 patients who received therapeutic heparin; no cases of thrombosis occurred in these patients. Major bleeding occurred in $8(3.0 \%)$ of the 266 patients who received prophylactic heparin and $9(3.4 \%)$ of the 268 who received no heparin $(p>0.99)$. Thrombosis occurred in $1(0.4 \%)$ and $3(1.1 \%)$ of these patients, respectively $(p=0.62)$. Major bleeding occurred more frequently among patients with a low-target heparin protocol, but $61 \%$ of values for partial thromboplastin time were above target. A larger proportion of deceaseddonor transplant recipients who had major bleeding were taking antiplatelet agents, relative to living-donor transplant recipients.

Conclusion: Therapeutic use of heparin increased the risk of bleeding among renal transplant recipients, but there were no cases of thrombosis. Prophylactic use of heparin did not increase the risk of bleeding and prevented proportionately more cases of thrombosis relative to no anticoagulation; this result supports the continued use of prophylaxis.

\section{RÉSUMÉ}

Contexte : Les troubles de l'hémostase sont courants chez les patients ayant subi une transplantation rénale. Comme il existe des risques de thromboembolie et de perte du greffon après une greffe, un protocole d'administration d'héparine prophylactique a été mis en place en 2011 à l'hôpital Saint-Paul de Vancouver, en Colombie-Britannique. On prescrit parfois l'héparine thérapeutique en période périopératoire à certains patients affligés d'un état prothrombotique préexistant. Il n'y a actuellement que peu de documentation sur la sécurité et l'efficacité de l'utilisation d'héparine au début de la période postopératoire.

Objectifs : Les objectifs principaux étaient de documenter les incidences de cas d'hémorragie importante et de thrombose chez les patients ayant subi une transplantation rénale et ayant reçu des doses thérapeutiques d'héparine, des doses prophylactiques d'héparine ou aucun anticoagulant au début de la période postopératoire ainsi que de comparer les incidences des cas entre les deux derniers groupes. Les objectifs secondaires incluaient la comparaison des facteurs de risque associés à une hémorragie importante et à une thrombose.

Méthodes : Les patients adultes retenus dans la présente étude de cohorte rétrospective avaient subi une greffe rénale à l'hôpital Saint-Paul entre janvier 2008 et juillet 2013. Des dossiers de santé informatisés et des bases de données ont servi à séparer les patients en trois cohortes selon l'utilisation ou non et la dose d'héparine afin de déceler les cas d'hémorragie importante et de thrombose et afin d'offrir un portrait des patients et des événements. Le test exact de Fisher a été employé pour l'analyse des principaux paramètres alors que l'on a utilisé des statistiques descriptives pour tous les autres paramètres.

Résultats : Au total, 547 patients ont été retenus pour l'analyse. Des hémorragies importantes ont été observées chez 6 (46\%) des 13 patients ayant reçu de l'héparine thérapeutique. Aucune thrombose n'a été relevée chez ces patients. Des hémorragies importantes ont été observées chez $8(3,0 \%)$ des 266 patients ayant reçu de l'héparine prophylactique et chez $9(3,4 \%)$ des 268 patients n'ayant pas reçu d'héparine $(p>0,99)$. Des thromboses ont été observées respectivement chez $1(0,4 \%)$ et $3(1,1 \%)$ de ces patients $(p=0,62)$. Un plus grand nombre de patients ont souffert d'hémorragies importantes avec un protocole à valeurs cibles inférieures pour l'administration d'héparine, mais $61 \%$ des valeurs pour le temps de thromboplastine partielle étaient au-dessus de la cible. Parmi les patients 
Keywords: kidney transplantation, heparin, postoperative anticoagulation, hemorrhage, thrombosis

\section{Can J Hosp Pharm. 2016;69(2):114-21}

qui ont souffert d'hémorragies importantes et dont le donneur était décédé, une plus grande proportion prenaient des antiplaquettaires.

Conclusion : L'administration thérapeutique d'héparine a accru les risques d'hémorragie chez les greffés rénaux, mais il n'y a pas eu de cas de thrombose. L'administration prophylactique d'héparine n'a pas augmenté les risques d'hémorragie et elle a permis d'éviter proportionnellement plus de cas de thrombose que l'absence d'anticoagulant; ce résultat vient appuyer l'utilisation d'héparine prophylactique.

Mots clés : transplantation rénale, héparine, anticoagulation postopératoire, hémorragie, thrombose

\section{INTRODUCTION}

$\mathrm{D}$ isturbances in hemostasis are common among renal transplant recipients. Patients who require renal transplant are those with end-stage renal disease; these patients also have pre-existing blood coagulation abnormalities associated with chronic kidney disease. ${ }^{1,2}$ Bleeding has been reported in up to $50 \%$ of patients with renal failure and is associated with defects in the secretory function and aggregation of platelets, defects in interactions between platelets and the vessel wall, and exposure to procedures. ${ }^{2}$ Patients with chronic kidney disease usually also have a hypercoagulable state due to sustained low-grade inflammation, which predisposes them to thrombotic complications at sites of vascular access. ${ }^{2}$ The causes of coexisting bleeding and thrombosis risk are not well understood. ${ }^{3}$ In addition, these patients may have pre-existing genetic and acquired hypercoagulable states. ${ }^{4}$

The process of renal transplant itself also presents significant risk for thrombosis. Perioperative stress can induce platelet aggregation, and the use of calcineurin inhibitors (e.g., cyclosporine A or tacrolimus) for immunosuppression may enhance agonistinduced platelet aggregation through modulation of protein phosphorylation. ${ }^{5}$ Furthermore, postoperative hypertensive episodes and additional insults to the vascular epithelium by cyclosporine A contribute to thromboembolism and have been hypothesized to trigger thrombosis in patients with previously asymptomatic sticky platelet syndrome. ${ }^{5}$ After renal transplant, the incidence of venous thromboembolism (VTE) is 6.2\%$18.1 \%$ and that of pulmonary embolism is $2 \%-14 \%$, with renal artery or vein thrombosis contributing to $45 \%$ of early renal graft losses. ${ }^{6,7}$ Moreover, the rate of recurrence after a first episode of VTE is much higher among renal transplant recipients than among matched patients without a history of renal disease $(50 \%$ versus $10 \%){ }^{8}$

Given the risk of VTE and graft loss, routine postoperative heparin prophylaxis has been implemented in many institutions, and a handful of studies have evaluated its use. One small study suggested that prophylactic subcutaneous (SC) heparin therapy produces a non-statistically significant reduction in thromboem- bolic complications, ${ }^{9}$ whereas other studies have suggested that prophylactic administration of heparin is not necessary in the early postoperative period for living-donor or deceased-donor renal transplant recipients with no other risk factors for VTE. ${ }^{10,11}$ Despite the paucity of strong evidence for VTE prophylaxis following renal transplant, a prophylactic VTE heparin protocol was implemented institution-wide at St Paul's Hospital, Vancouver, British Columbia, in 2011. Before 2011, most renal transplant recipients at this institution received no postoperative anticoagulation unless there was an indication for therapeutic heparin. Since then, postoperative prophylaxis with unfractionated heparin (UFH) or low-molecular-weight heparin has become the standard of care for renal transplant recipients with no contraindications to such therapy.

There are various indications for patients to receive early therapeutic anticoagulation instead of thromboprophylaxis, including a pre-existing mechanical heart valve, pre-existing VTE, or atrial fibrillation. The 2012 guidelines of the American College of Chest Physicians recommend perioperative therapeutic heparin anticoagulation in high-risk patients during cessation of vitamin $\mathrm{K}$ antagonist; however, it was also acknowledged that further research is needed to inform best perioperative practices in special populations such as those with renal insufficiency. ${ }^{12}$ Although there have been no randomized controlled trials on the topic of postoperative therapeutic anticoagulation in renal transplant recipients, 3 retrospective studies, summarized in the following paragraphs, have evaluated the use of therapeutic anticoagulation in high-risk patients after kidney transplant. ${ }^{4,13,14}$

Mathis and others ${ }^{4}$ conducted a retrospective analysis of 725 consecutive renal transplant recipients to identify factors associated with bleeding and thrombosis. Twenty-eight of the patients received UFH 500-1100 units/h starting 1-12 h after the surgery was completed, of whom 18 experienced bleeding; 14 of these bleeding episodes were considered major. However, delayed graft function did not seem to be associated with bleeding risk, and the presence of a hypercoagulable state did not seem to predict bleeding risk. Factors that contributed to bleeding 
appeared to be high partial thromboplastin time (PTT) ratios and antimicrobial prophylaxis with cefotetan, which can disrupt production of vitamin $\mathrm{K}$-dependent clotting factors. Thrombosis occurred in 3 patients with PTT ratios below 1.5; therefore, Mathis and others ${ }^{4}$ suggested that the optimal PTT ratio is 1.5-1.9.

Kusyk and others ${ }^{13}$ conducted a retrospective analysis of 326 renal allograft recipients to compare postoperative courses between patients who did and did not receive early IV UFH. The UFH was started a median of 8 (interquartile range 1-14) days after the transplant procedure. ${ }^{13}$ Sixteen of the patients received therapeutic IV UFH at 500-1000 units/h, of whom $62.5 \%$ experienced sustained hemorrhagic complications, compared with $3.5 \%$ of 310 patients who did not receive heparin. Hemorrhagic complications requiring major intervention occurred in $37.5 \%$ of the UFH recipients, compared with $2.2 \%$ of those who did not receive heparin. However, there were no allograft losses and no episodes of thrombosis among the 16 patients who received UFH, whereas 3 allografts were lost due to renal vein thrombosis among the 310 patients without anticoagulation. ${ }^{13}$ The statistical significance of this observation was not specified.

In a retrospective study, Ringenberg and others ${ }^{14}$ found a higher rate of bleeding among 29 renal transplant recipients who were receiving UFH by IV infusion for VTE, atrial fibrillation, and acute coronary syndromes than among 29 patients who did not undergo transplant but were receiving UFH ( $31 \%$ versus $6.9 \%, p=0.041)$. In this study, bleeding events were identified by findings from magnetic resonance imaging, computed tomography, or procedures such as endoscopy or colonoscopy or by symptoms of bleeding, such as hematuria, hematoma, or melena. These authors also found a higher, though statistically nonsignificant, drop in hemoglobin $(\geq 10 \mathrm{~g} / \mathrm{L})$ or need for transfusion in transplant recipients relative to those who did not receive a transplant $(p=0.111)$. However, because the study was designed to assess the safety of IV UFH, efficacy data were not captured..$^{14}$

In summary, there is currently limited information on the safety and efficacy of using early postoperative therapeutic heparin anticoagulation for valid indications in patients who have undergone renal transplant. However, at the study institution, anecdotal observations suggested a high rate of postoperative bleeding complications in patients receiving this form of anticoagulation.

The primary objectives of this study were to determine the incidence of bleeding and of thrombosis in renal transplant recipients receiving therapeutic heparin, prophylactic heparin, and no heparin anticoagulation in the early postoperative phase, and to compare these rates between the prophylactic heparin and noheparin cohorts. The secondary objectives were to compare coagulation parameters and risk factors related to episodes of bleeding and thrombosis in the 3 cohorts, to determine the indications for therapeutic anticoagulation, and to determine the interventions and outcomes of major bleeding and thrombosis complications.

\section{METHODS}

\section{Study Design and Setting}

This retrospective cohort study involved patients who underwent kidney transplant at St Paul's Hospital. The study was approved by the University of British Columbia Providence Health Care Research Ethics Board and the Fraser Health Research Ethics Board.

\section{Participants}

Patients who were at least 19 years of age and who had undergone kidney transplant at St Paul's Hospital between January 1, 2008, and July 31, 2013, were included in the study. Eligible patients were identified using the Patient Records and Outcome Management Information System (PROMIS) database of the BC Renal Agency. Centricity Pharmacy software (General Electric Healthcare Integrated Information Technology Solutions, Barrington, Illinois) was used to identify patients who received no heparin, prophylactic heparin, or therapeutic heparin anticoagulation in the early postoperative period, defined as postoperative days $0-7$. Patients were stratified to their respective heparin cohorts.

\section{Sample Size}

It was estimated that a total of 580 patients received a kidney transplant within the specified time frame, which represented a sample size of convenience.

\section{Outcome Variables for Primary Objective}

The incidences of major bleeding and of thrombosis in the early postoperative period were determined for the 3 cohorts, and were compared between the prophylactic heparin and noheparin-anticoagulation cohorts. Major bleeding was defined as hematoma requiring surgical evacuation, retroperitoneal bleeding, intracranial bleeding, documented bleeding requiring 2 or more units of packed red blood cells, or documented bleeding with a drop in hemoglobin level of $20 \mathrm{~g} / \mathrm{L}$ or more. ${ }^{4}$ Thromboses were identified from documentation related to both arterial and venous thromboembolic events.

\section{Outcome Variables for Secondary Objectives}

Risk factors assessed in comparing patients with major bleeding and no bleeding were preoperative use of antiplatelet agents (namely acetylsalicylic acid and clopidogrel) and the type of kidney transplant (deceased donor or living donor). For living-donor transplants, which are planned in advance, antiplatelet agents are held for at least 5 days preoperatively to decrease the risk of bleeding during and after the procedure. In contrast, deceased-donor transplants allow for little preparation time because of the urgent nature of the procedure; as such, antiplatelet agents cannot be held preoperatively. 
For patients who received therapeutic heparin, the proportion of measured PTT values within, below, and above target were determined and compared.

For patients who experienced major bleeding and thrombosis, the following hematological and coagulation parameters were compared between the cohorts (all reported as means with standard deviation [SD]): hemoglobin at various time points (preoperatively, immediately postoperatively, and at time of the event); hemoglobin nadir during the hospital stay; drop in hemoglobin associated with the event; and PTT, international normalized ratio, and platelet count at the time of the event. Risk factors assessed were duration of prophylactic or therapeutic heparin (if applicable), duration of event, concurrent conditions, relevant prior-to-admission medications, and relevant medications administered within the last $24 \mathrm{~h}$ of the event. Relevant concurrent conditions that would increase bleeding risk were any hematological and coagulation disorders. Relevant medications that would increase bleeding risk were acetylsalicylic acid, clopidogrel, nonsteroidal anti-inflammatory drugs, warfarin, new oral anticoagulants, heparin, low-molecular-weight heparins, nonheparin anticoagulants, and selective serotonin reuptake inhibitor/serotonin-norepinephrine reuptake inhibitor antidepressants. Conditions that would increase thromboembolic risk were history of malignancy, heart failure, inflammatory bowel disease, obesity, and antiphospholipid or anticardiolipin antibodies. Medications that would increase thromboembolic risk were oral contraceptives, hormone replacement therapies, tamoxifen, and bevacizumab.

The indications for initiation of therapeutic heparin anticoagulation were determined. Finally, the nature of the major bleeding and thrombosis complications, the interventions administered, and patients' final outcomes were also characterized.

All data were collected from the PROMIS, Centricity, and Sunrise Clinical Manager (Eclipsys Corporation, Boca Raton, Florida) databases at St Paul's Hospital.

\section{Statistical Analysis}

Descriptive analysis was used for demographic variables and secondary outcome variables. Continuous variables are expressed as means with SDs. The Fisher exact test was used to compare the incidences of thrombosis and of major bleeding between the prophylactic heparin and no-heparin groups. Statistical significance was defined by $p$ values less than 0.05 . The incidences of bleeding and of thrombosis in the therapeutic heparin group were not compared with those in the prophylactic heparin and no-heparin groups, as the former group was inherently at a higher risk of bleeding or thrombosis, which made comparisons with the other groups less meaningful. A statistician from the BC Provincial Renal Agency was consulted for statistical analysis.

\section{RESULTS}

The total transplant population consisted of 547 patients, of whom 268 received no heparin in the early postoperative period, 266 received prophylactic heparin, and 13 received therapeutic heparin. Of the 266 patients who received prophylactic heparin, 242 (91.0\%) received heparin 5000 units SC twice daily, 17 (6.4\%) received dalteparin 5000 units SC daily, and $7(2.6 \%)$ received heparin SC at a nonstandard dosage (7500 units q8h or 5000 units q8h). Of the 13 patients who received therapeutic heparin, 4 received a second course of heparin, for a total of 17 courses overall (all given intravenously). Eleven (65\%) of these 17 courses used a low-target protocol (target PTT $50-85 \mathrm{~s})$, and the other 6 courses (35\%) used a standard-target protocol (target PTT 60-120 s).

Baseline patient demographic characteristics are shown in Table 1. Overall, $328(60.0 \%)$ of the 547 patients were men, and $260(47.5 \%)$ received a deceased-donor renal transplant; the mean age was 51.5 (SD 13.3) years, and mean body mass index was 26.1 (SD 5.0) $\mathrm{kg} / \mathrm{m}^{2}$. Patients who received therapeutic heparin were substantially older and had a longer length of stay compared with the other 2 cohorts. The temporal distribution of patients in the prophylactic and no-heparin cohorts reflected the institution-wide implementation of the heparin prophylaxis protocol in 2011: the majority of patients in the no-heparin cohort received their transplant between 2008 and 2010, whereas most of the patients in the prophylactic cohort received their transplant from 2011 onward.

\section{Primary Outcomes}

Twenty-four (4.4\%) of the patients experienced a total of 27 episodes of major bleeding or thrombosis; of these, 3 patients had both bleeding and thrombosis. There were 23 episodes of major bleeding ( $4.2 \%$ of patients). The incidence of major bleeding was 46\% (6/13) in the therapeutic heparin group, 3.0\% (8/266) in the prophylactic heparin group, and 3.4\% (9/268) in the no-heparin group $(p>0.99$ for comparison between prophylactic heparin and no-heparin groups). There were 4 thrombotic episodes ( $0.7 \%$ of patients), including 3 episodes in patients who experienced both bleeding and thrombosis. No cases of thrombosis were documented in the therapeutic heparin group, whereas the incidence of thrombosis was $0.4 \%(1 / 266)$ in the prophylactic heparin group and 1.1\% (3/268) in the no-heparin group ( $p=0.62$ for comparison between prophylactic heparin and no-heparin groups).

\section{Secondary Outcomes}

Figure 1 shows preoperative antiplatelet use for deceaseddonor and living-donor transplant recipients with and without major bleeding. Figure 2 depicts the proportions of PTT values within and outside the target range for therapeutic heparin treatments, categorized by low-target (PTT range 50-85 s) and standard-target (PTT range 60-120 s) protocols, and by major bleeding or no bleeding. 
This single copy is for your personal, non-commercial use only.

For permission to reprint multiple copies or to order presentation-ready copies for distribution, contact CJHP at cjhpedit@cshp.ca

Table 1. Baseline Demographic Characteristics

Group; No. (\%) of Patients or Mean \pm SD

\begin{tabular}{|c|c|c|c|c|c|c|c|c|}
\hline \multirow{2}{*}{$\begin{array}{l}\text { Parameter } \\
\text { Sex, male }\end{array}$} & \multicolumn{2}{|c|}{$\begin{array}{c}\text { No Heparin } \\
(n=268)\end{array}$} & \multicolumn{2}{|c|}{$\begin{array}{c}\text { Prophylactic } \\
\text { Heparin }(n=266)\end{array}$} & \multicolumn{2}{|c|}{$\begin{array}{c}\text { Therapeutic } \\
\text { Heparin }(n=13)\end{array}$} & \multicolumn{2}{|c|}{$\begin{array}{c}\text { Overall } \\
(n=547)\end{array}$} \\
\hline & 158 & $(59.0)$ & 162 & $(60.9)$ & 8 & $(62)$ & 328 & $(60.0)$ \\
\hline Prior transplant loss & 33 & $(12.3)$ & 11 & $(4.1)$ & 4 & (31) & 48 & $(8.8)$ \\
\hline \multicolumn{9}{|l|}{ Transplant type } \\
\hline Living & 148 & $(55.2)$ & 134 & $(50.4)$ & 5 & (38) & 287 & $(52.5)$ \\
\hline Deceased donor & 120 & (44.8) & 132 & (49.6) & 8 & $(62)$ & 260 & $(47.5)$ \\
\hline Age (years) & \multicolumn{2}{|c|}{$50.4 \pm 13.1$} & \multicolumn{2}{|c|}{$52.4 \pm 13.2$} & \multicolumn{2}{|c|}{$57.5 \pm 16.3$} & \multicolumn{2}{|c|}{$51.5 \pm 13.3$} \\
\hline BMI $\left(\mathrm{kg} / \mathrm{m}^{2}\right)$ & \multicolumn{2}{|c|}{$25.7 \pm 5.3$} & \multicolumn{2}{|c|}{$26.4 \pm 4.7$} & \multicolumn{2}{|c|}{$26.9 \pm 5.5$} & \multicolumn{2}{|c|}{$26.1 \pm 5.0$} \\
\hline \multicolumn{9}{|l|}{ Laboratory investigations } \\
\hline $\mathrm{SCr}(\mu \mathrm{mol} / \mathrm{L})$ & \multicolumn{2}{|c|}{$546.8 \pm 239.5$} & \multicolumn{2}{|c|}{$545.9 \pm 261.4$} & \multicolumn{2}{|c|}{$485.0 \pm 192.9$} & \multicolumn{2}{|c|}{$544.9 \pm 249.2$} \\
\hline Platelets $\left(\times 10^{9} / \mathrm{L}\right)$ & \multicolumn{2}{|c|}{$177.1 \pm 63.2$} & \multicolumn{2}{|c|}{$184.5 \pm 57.5$} & \multicolumn{2}{|c|}{$168.9 \pm 48.1$} & \multicolumn{2}{|c|}{$180.5 \pm 60.2$} \\
\hline Hemoglobin (g/L) & \multicolumn{2}{|c|}{$105.8 \pm 15.4$} & \multicolumn{2}{|c|}{$104.4 \pm 14.5$} & \multicolumn{2}{|c|}{$104.7 \pm 12.5$} & \multicolumn{2}{|c|}{$105.1 \pm 14.9$} \\
\hline PTT (s) & \multicolumn{2}{|c|}{$32.5 \pm 8.0$} & \multicolumn{2}{|c|}{$31.65 \pm 8.49$} & \multicolumn{2}{|c|}{$40.4 \pm 16.6$} & \multicolumn{2}{|c|}{$32.3 \pm 8.6$} \\
\hline INR & 1.1 & 0.2 & 1.09 & \pm 0.15 & & \pm 0.1 & 1.1 & \pm 0.2 \\
\hline Length of admission (days) & 7.8 & 12.9 & 8.5 & \pm 17.4 & 18.9 & \pm 17.4 & 8.3 & \pm 15.4 \\
\hline Transplant year & & & & & & & & \\
\hline $2008-2010$ & 243 & $(90.7)$ & 14 & (5.3) & 8 & $(62)$ & 265 & $(48.4)$ \\
\hline $2011-2013^{*}$ & 25 & (9.3) & 252 & $(94.7)$ & 5 & (38) & 282 & $(51.6)$ \\
\hline $\begin{array}{l}\text { Comorbid conditions withir } \\
6 \text { months of transplant dat }\end{array}$ & & & & & & & & \\
\hline Diabetes mellitus & 82 & $(30.6)$ & 100 & $(37.6)$ & 3 & $(23)$ & 185 & $(33.8)$ \\
\hline Hypertension & 210 & (78.4) & 229 & $(86.1)$ & 9 & (69) & 448 & $(81.9)$ \\
\hline Malignancy & 22 & $(8.2)$ & 22 & (8.3) & 2 & (15) & 46 & $(8.4)$ \\
\hline Coronary artery disease & 52 & $(19.4)$ & 65 & $(24.4)$ & 5 & (38) & 122 & $(22.3)$ \\
\hline Cerebrovascular events & 9 & (3.4) & 9 & (3.4) & 0 & (0) & 18 & (3.3) \\
\hline Myocardial infarction & 11 & $(4.1)$ & 18 & (6.8) & 2 & (15) & 31 & $(5.7)$ \\
\hline Congestive heart failure & 17 & (6.3) & 14 & (5.3) & 1 & (8) & 32 & (5.9) \\
\hline Dysrhythmia & 11 & (4.1) & 13 & (4.9) & 1 & (8) & 25 & (4.6) \\
\hline
\end{tabular}

$\mathrm{BMI}=$ body mass index, INR = international normalized ratio, PTT = partial thromboplastin time,

$\mathrm{SCr}=$ serum creatinine, $\mathrm{SD}=$ standard deviation.

*Up to and including July 31, 2013.

Hematological and coagulation parameters for patients with a major bleeding event are presented in Table 2. Notably, the onset of major bleeding occurred a mean of 2.3 (SD 1.8) days after initiation of anticoagulation, and the mean drop in hemoglobin associated with major bleeding was 40.0 (SD 8.4) g/L. In terms of potential factors for increased bleeding risk, no patients were identified as having any hematological or coagulation disorder. Notable medications before admission included acetylsalicylic acid $81 \mathrm{mg}$ daily, which was being taken by $5(56 \%)$ of the 9 patients in the no-heparin group, $3(38 \%)$ of the 8 patients in the prophylactic heparin group, and 4 (67\%) of the 6 patients in the therapeutic heparin group. Another notable medication was warfarin, with frequencies of $0(0 \%)$ of 9 patients, $2(25 \%)$ of 8 patients, and $1(17 \%)$ of 6 patients, respectively. No trends were identified regarding medications administered within the last $24 \mathrm{~h}$ of the major bleed, except for use of intraoperative heparin irrigation in $7(78 \%)$ of 9 patients, $1(12 \%)$ of 8 patients, and $0(0 \%)$ of 6 patients, respectively. The mean duration of prophylactic heparin was 5.6 (SD 2.5) days, and the mean duration of therapeutic heparin was 3.1 (SD 1.3) days.

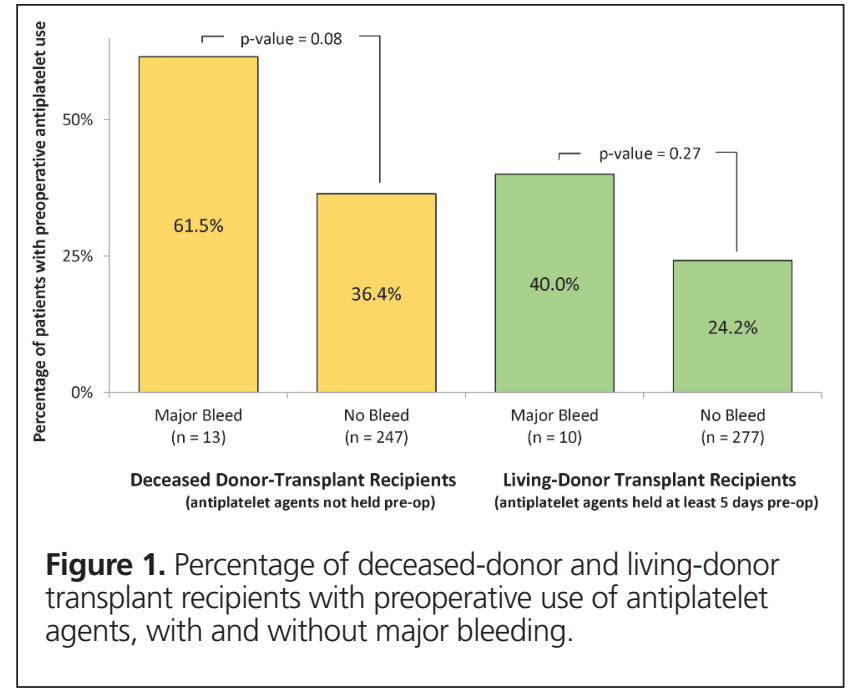

Among the 4 patients with a thrombotic event, the overall mean onset of thrombosis after transplant was $4.2 \pm 2.3$ days. No differences in hematological and coagulation parameters were noted for these patients. In terms of factors potentially increasing the risk of thrombosis, 1 patient in the no-heparin group had 


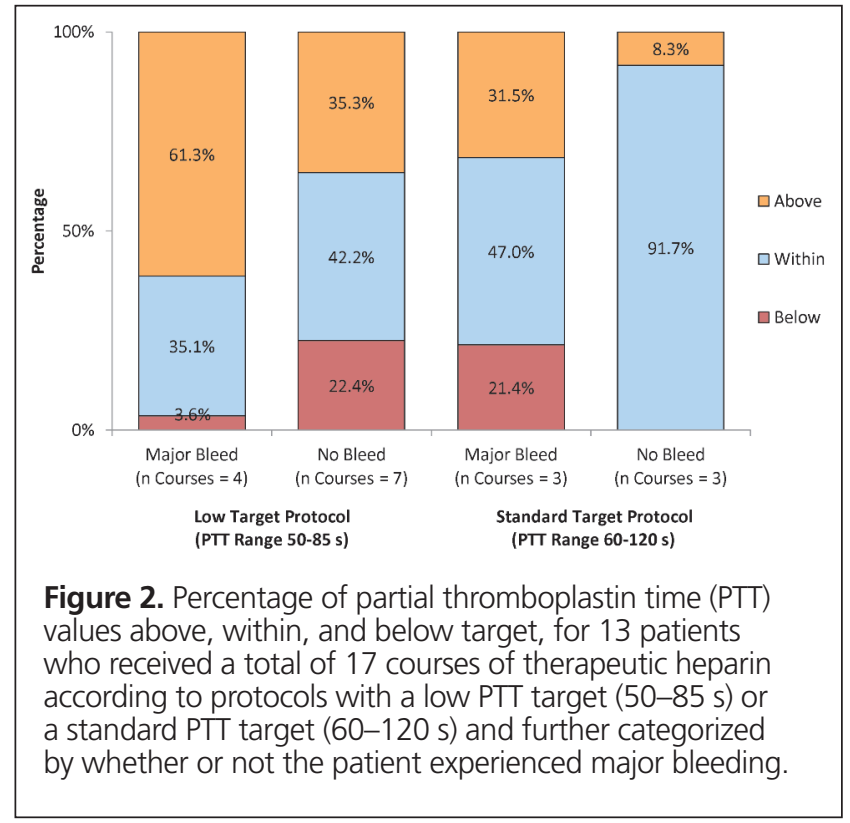

heart failure, and 1 patient in each of the prophylactic heparin and no-heparin groups was obese. None of the patients who experienced a thrombotic event had a history of recent malignancy, inflammatory bowel disease, or antiphospholipid or anticardiolipin antibodies, and none of these patients had taken relevant medications before admission or within $24 \mathrm{~h}$ before the thrombosis occurred. For the single patient who received prophylactic heparin and experienced a thrombotic episode, the duration of prophylactic heparin use was 3 days.

Indications for therapeutic use of heparin were the following: positive for factor $\mathrm{V}$ Leiden, postoperative myocardial infarction, postoperative transplant rejection with thrombosis requiring thrombectomy, history of deep vein thrombosis with uncertain hypercoagulable state, new-onset paroxysmal atrial fibrillation, postoperative bilateral pulmonary emboli originating from bilateral deep vein thrombosis in a calf vein, history of anticardiolipin antibodies, history of pulmonary embolism, and mechanical aortic valve.

Of note, 14 (61\%) of the 23 major bleeding events were retroperitoneal hematomas, and 13 (57\%) necessitated infusion of packed red blood cells (range 1-10 units); 3 cases (13\%) required no intervention. Of the 4 thrombotic events, 3 resulted in nephrectomy due to a nonfunctioning graft. Most of the patients who experienced major bleeding or thrombosis were ultimately stabilized and discharged. Three of the patients (one with major bleeding only, one with thrombosis only, and one with both major bleeding and thrombosis) eventually died, but because of numerous complicating factors, including infection and sepsis, their deaths could not be easily attributed to their major events.

\section{DISCUSSION}

In this study, the incidence of major bleeding in each cohort was similar to that reported in the literature. ${ }^{4,13}$ As expected, therapeutic heparin was associated with a higher rate of major bleeding, relative to prophylactic heparin and no heparin anticoagulation: $46 \%, 3.0 \%$, and $3.4 \%$, respectively. Therapeutic heparin was effective for patients deemed to be at very high risk of thrombosis, and no thrombosis was observed in these patients. Above-target PTT was identified as a risk factor for bleeding, especially in the low-target group. Overall, there were fewer bleeding episodes in the low-target group than in the standardtarget group. Because no thrombosis was noted with the use of either heparin protocol, these data suggest that use of the low-target protocol and achievement of the target PTT may provide an acceptable balance between therapeutic anticoagulation and risk of bleeding.

Interestingly, there was no statistically significant difference in the incidence of major bleeding between the prophylactic heparin and no-heparin groups, which suggests that the use of

Table 2. Comparison of Hematological and Coagulation Parameters in Patients with Major Bleeding Events

Group; Mean \pm SD

\begin{tabular}{|c|c|c|c|c|}
\hline \multirow[b]{2}{*}{ Parameter } & \\
\hline & $\begin{array}{l}\text { No Heparin } \\
(n=9)\end{array}$ & $\begin{array}{l}\text { Prophylactic } \\
\text { Heparin }(n=8)\end{array}$ & $\begin{array}{c}\text { Therapeutic } \\
\text { Heparin }(n=6)\end{array}$ & $\begin{array}{l}\text { Overall } \\
(n=23)\end{array}$ \\
\hline $\begin{array}{l}\text { Time to major bleeding after } \\
\text { transplant (days) }\end{array}$ & $1.5 \pm 1.2$ & $2.7 \pm 2.2$ & $3.2 \pm 1.5$ & $2.3 \pm 1.8$ \\
\hline \multicolumn{5}{|l|}{ Hemoglobin (g/L) } \\
\hline Preoperative & $129.4 \pm 8.7$ & $125.5 \pm 11.2$ & $120.5 \pm 11.8$ & $125.7 \pm 10.6$ \\
\hline Immediately after surgery & $104.7 \pm 12.9$ & $108.6 \pm 19.8$ & $101.7 \pm 8.6$ & $105.3 \pm 14.5$ \\
\hline At time of bleeding event & $77.2 \pm 12.6$ & $83.1 \pm 16.9$ & $74.3 \pm 3.8$ & $78.5 \pm 12.8$ \\
\hline Nadir after bleeding event & $69.3 \pm 11.3$ & $72.1 \pm 14.4$ & $63.0 \pm 4.4$ & $68.7 \pm 11.4$ \\
\hline Decrease associated with bleeding & $39.4 \pm 8.7$ & $41.8 \pm 10.2$ & $38.7 \pm 6.3$ & $40.0 \pm 8.4$ \\
\hline INR at time of event & $1.4 \pm 0.2$ & $1.4 \pm 0.4$ & $1.2 \pm 0.2$ & $1.4 \pm 0.3$ \\
\hline PTT at time of event (s) & $43.0 \pm 23.7$ & $38.0 \pm 9.0$ & $66.2 \pm 41.4$ & $47.3 \pm 27.5$ \\
\hline $\begin{array}{l}\text { Platelet count at time of } \\
\text { event }\left(\times 10^{9} / \mathrm{L}\right)\end{array}$ & $95.0 \pm 33.0$ & $171.8 \pm 84.9$ & $133.5 \pm 40.9$ & $131.7 \pm 64.8$ \\
\hline
\end{tabular}


prophylaxis was as safe as not using heparin at all, in terms of risk of bleeding. With respect to effectiveness, the rate of thrombosis was higher in the no-heparin group (1.1\%) than in the prophylactic heparin group $(0.4 \%)$. Although this difference was not statistically significant, it may be a signal suggesting that the use of prophylaxis was safe and effective in reducing thrombosis. As expected, the use of antiplatelet agents was associated with bleeding. Although the difference was not statistically significant, bleeding was more pronounced among recipients of deceaseddonor transplants, who received an antiplatelet agent right up to the time of surgery, than among living-donor recipients, whose antiplatelet therapy was held preoperatively. Cautious monitoring could be exercised in this group with higher bleeding risk.

Data for coagulation parameters and risk factors did not show any further noteworthy trends for high-risk medical conditions or medications that increased patients' risk for major bleeding or thrombosis. This finding points to the complexity of interacting factors that affect hemostasis in renal transplant recipients. Two of the 4 patients who experienced thrombosis were obese, and obesity is a risk factor for thrombosis; however, the number of events was too small to draw any conclusions.

The interventions used to address each event varied, depending on multiple patient factors; the only common intervention among patients with major bleeding was the infusion of packed red blood cells. This variation points to the multitude of complications that may occur with kidney transplant.

\section{Limitations}

This study had some limitations that could affect interpretation of the results. First, as a retrospective study, this research was limited to data identified by reviewing electronic databases and scanned charts, but such records may be incomplete and inconsistent (e.g., in terms of a patient's medication history). In particular, the study relied heavily on dictated discharge summaries to identify and verify major events. However, it is likely that the medical team documented major bleeding or thrombotic events in patients' discharge summaries, so most or all such events were probably identified. As well, there were fewer patients who received therapeutic heparin than anticipated. As such, there was a smaller number of events, which made it difficult to draw any strong conclusions about particular therapies (e.g., low-target heparin protocol or antiplatelet use). Since the incidence of major bleeding in this patient population was similar to that reported in the literature, the small number of events was attributed to the inadequate sample size. In addition, the study results were drawn from a small sample at a single centre, and therefore may not be generalizable to other practice sites. In terms of stratifying patients into the correct cohort, it was not possible to verify whether doses were actually administered for all the heparin orders entered in the pharmacy database; therefore, it is uncertain whether some patients in the prophylactic heparin cohort actually received therapy. However, therapeutic heparin was likely to have been administered, as changes in PTT were documented in patients' charts. The difference in time frame between the prophylactic heparin and no-heparin groups was noted (as described above), but no procedural or treatment changes that might have affected bleeding or thrombosis during these time periods were reported by the transplant physicians. In addition, there was subjectivity in determining the start time of major bleeding or thrombosis events. Finally, minor bleeding events were not captured in this study because of the difficulty of reliably identifying such events in a retrospective analysis.

\section{CONCLUSION}

Therapeutic use of heparin increased the risk of bleeding in post-renal transplant patients, but there were no cases of thrombosis. Prophylactic use of heparin did not increase bleeding and appeared to prevent thrombosis relative to no heparin. There was no clear signal explaining the occurrence of major bleeding or thrombosis. The results of this study support the continued use of prophylactic heparin anticoagulation in this patient population; they also signal that a low-target heparin protocol should be used for therapeutic anticoagulation, to minimize bleeding episodes.

\section{References}

1. Suthanthiran M, Strom TB. Renal transplantation. N Engl J Med. 1994; 331(6):365-76.

2. Pavord S, Myers B. Bleeding and thrombotic complications of kidney disease. Blood Rev. 2011;25(6):271-8.

3. Jalal D, Chonchol M, Targher G. Disorders of hemostasis associated with chronic kidney disease. Semin Thromb Hemost. 2010;36(1):34-40.

4. Mathis AS, Davé N, Shah NK, Friedman GS. Bleeding and thrombosis in high-risk renal transplantation candidates using heparin. Ann Pharmacother. 2004;38(4):537-43.

5. Mühlfeld AS, Ketteler M, Schwamborn K, Eitner F, Schneider B, Gladziwa U, et al. Sticky platelet syndrome: an underrecognized cause of graft dysfunction and thromboembolic complications in renal transplant recipients. Am J Transplant. 2007;7(7):1865-8.

6. Guirguis NG, Eicher C, Hock L, Lynch J, Graham VD, Rajagopalan PR, et al. Thromboembolic risk factors in patients undergoing kidney transplant: implication of abnormally short activated partial thromboplastin time. Ann Clin Lab Sci. 2003;33(4):396-400.

7. Bakir N, Sluiter WJ, Ploeg RJ, van Son WJ, Tegzess AM. Primary renal graft thrombosis. Nephrol Dial Transplant. 1996;11(1):140-7.

8. Poli D, Zanazzi M, Antonucci E, Marcucci R, Rosati A, Bertoni E, et al. High rate of recurrence in renal transplant recipients after a first episode of venous thromboembolism. Transplant. 2005;80(6):789-93.

9. Ubhi CS, Lam FT, Mavor AID, Giles GR. Subcutaneous heparin therapy for cyclosporine-immunosuppressed renal allograft recipients. Transplant. 1989;48(5):886-7.

10. Osman Y, Kamal M, Soliman S, Sheashaa H, Shokeir A, Shehab El-Dein AB. Necessity of routine postoperative heparinization in non-risky live-donor renal transplantation: results of a prospective randomized trial. Urology. 2007;69(4):647-51. 
11. Bakkaloglu H, Salmaslioglu A, Tunca F, Serin KR, Agcaoglu O, Nane I, et al. Is heparinization necessary in the early postoperative period of renal transplantation from cadaveric donors? Transplant Proc. 2012;44(6):1690-3.

12. Douketis JD, Spyropoulos AC, Spencer FA, Mayr M, Jaffer AK, Eckman $\mathrm{MH}$, et al. Perioperative management of antithrombotic therapy: Antithrombotic Therapy and Prevention of Thrombosis, 9th ed: American College of Chest Physicians evidence-based clinical practice guidelines. Chest. 2012; 141(2 Suppl):e326S-50S.

13. Kusyk T, Verran D, Stewart G, Ryan B, Fisher J, Tsacalos K, et al. Increased risk of hemorrhagic complications in renal allograft recipients receiving systemic heparin early posttransplantation. Transplant Proc. 2005;37(2):1026-8.

14. Ringenberg T, Desanto H, Opsha Y, Costello J, Schiller D. Evaluation of bleeding rates in renal transplant patients on therapeutic intravenous heparin. Hosp Pharm. 2013;48(11):936-57.

Joan Chung Yan Ng, BSC(Pharm), ACPR, was, at the time of this study, a Pharmacy Resident with Lower Mainland Pharmacy Services in Vancouver, British Columbia. She is now a Clinical Pharmacist with Providence Health Care and a student in the graduate Doctor of Pharmacy program at the University of British Columbia, Vancouver, British Columbia.

Marianna Leung, BSC(Pharm), ACPR, PharmD, is a Clinical Pharmacy Specialist, Transplant, with Providence Health Care, and a Clinical Assistant Professor with the University of British Columbia, Vancouver, British Columbia
David Landsberg, MD, FRCPC, is Renal Program Director with Providence Health Care, Medical Director of Kidney Transplantation with the BC Transplant Society, and Clinical Professor with the University of British Columbia, Vancouver, British Columbia.

Competing interests: None declared.

\section{Address correspondence to:}

Joan Chung Yan Ng

Pharmacy

St Paul's Hospital

108 Burrard Street

Vancouver BC V6Z 1Y6

e-mail: joancyng@alumni.ubc.ca

Funding: None received.

Acknowledgements: The authors thank John Gill, MD, Jagbir Gill, MD, Gary Nussbaumer, MD, and Clare Bannon, RN, for the initial concept for the research project. As well, special thanks go to Natasha Kwan and Anna Yee for their tireless assistance in the data collection process, and to Lee Er, statistician at the BC Provincial Renal Agency, for her assistance with the statistical analyses.

\section{Compounding: Guidelines for Pharmacies 2014}

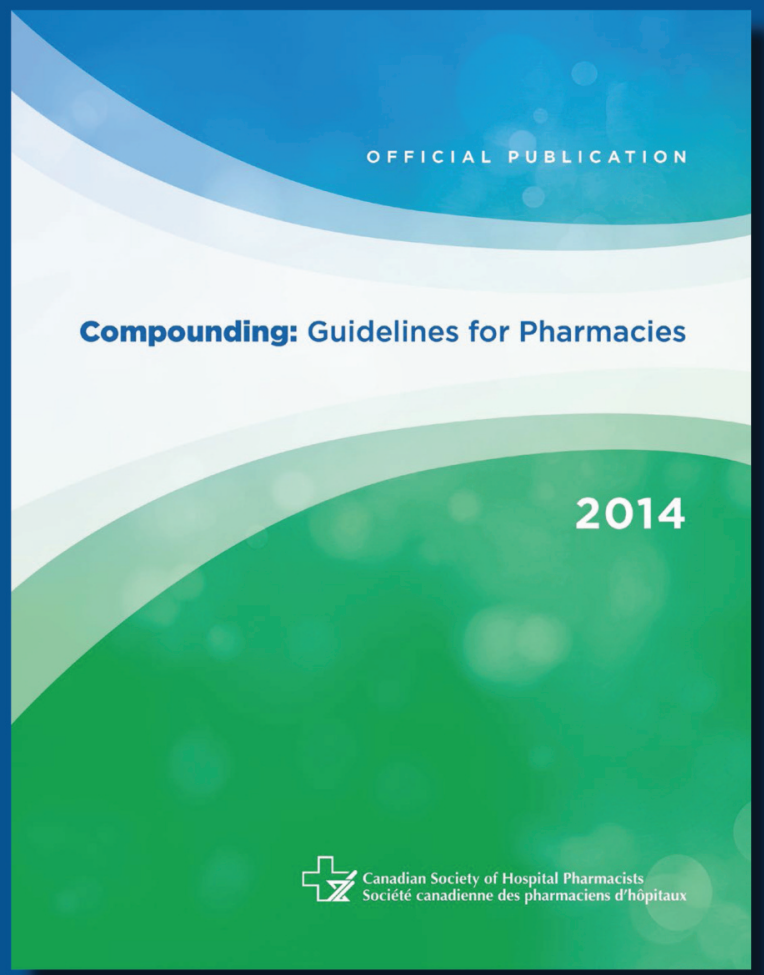

The Canadian Society of Hospital Pharmacists' comprehensive set of guidelines covers the compounding in pharmacies whenever compounded preparations are intended for human use, regardless of the route of administration or whether the preparation is related to research purposes. These guidelines also apply to the preparation of radiopharmaceuticals and other hazardous pharmaceuticals.

Find our order form here: http://www. cshp.ca/dms/dmsView/I CSHP-Publications-form-Jan2015.pdf

Contact the CSHP Publications Administrator for more information:

E: aiannaccio@cshp.ca

P: 6|3-736-9733 x:228 